\title{
The Profile of the Supervising Lecturer: On the Association between Supervision Outputs and the Nature of the Supervision
}

\author{
Nitza Davidovitch ${ }^{1} \&$ Eyal Eckhaus ${ }^{2}$ \\ ${ }^{1}$ Head of Academic Quality and Assessment, Head of Teacher Training Program, Ariel University, Ariel, Israel \\ ${ }^{2}$ Department of Economics and Business Administration, Ariel University, Ariel, Israel \\ Correspondence: Eyal Eckhaus, Department of Economics and Business Administration, Ariel University, Ariel, \\ Israel. E-mail: eyale@ ariel.ac.il
}

Received: September 10, 2020

Accepted: October 10, 2020

Online Published: October 31, 2020

doi:10.5539/hes.v10n4p62

URL: https://doi.org/10.5539/hes.v10n4p62

\begin{abstract}
This study is a pioneer study that seeks to explore the association between supervision outputs and the nature of the supervision (by e-mail, face-to-face, the student's independence). In addition, the association between the supervising lecturer's personal background (gender, age), professional background (faculty, tenure, excellence in teaching), and the supervision outputs (articles written, presentations at conferences) and nature of the supervision is explored. The purpose of the study is to explore items in depth so that they can be used in developing a questionnaire exploring the association between supervision outputs and the nature of the supervision.

The research findings show, for various items, significant interactions between age and gender, excellence in teaching, and tenure. Significant interactions were also found between gender and faculty, as well as between age and excellence in teaching. Differences were also found between faculties.

The findings of this study might have practical consequences for establishing the output-guided association in research supervision, as well as for establishing the practical association between the nature of the supervision and the lecturer's personal background, professional background, the supervision outputs, and the nature of the supervision. These findings constitute a foundation for methodological thinking concerning supervision by staff members, a subject that has considerable meaning for the initial steps taken by young student researchers and for the systematic establishment of the pattern of academic supervision, which although not frontal teaching may be even more demanding.
\end{abstract}

Keywords: academy, supervision, research, survey development, education

\section{Introduction}

A key step in developing a survey instrument is the generation of items to be measured (Dupuis, Crossler \& Endicott-Popovsky, 2016), and requires quantifying the factors to be studied (Sachs, 2004). Developing a questionnaire is not a simple process, and it includes preparation of the questions (Väätäjä, Koponen \& Roto, 2009). Developing a questionnaire is critical for the success of the survey because ambiguous questions, inappropriate wording, and the length of the questionnaire can affect the response rate (Farooq, 2018).

The purpose of this study is to develop items on the subject of supervision outputs and in-depth analysis of their association with demographic and professional variables of supervisors, in order to utilize the items in an efficient and precise instrument in future studies.

Results of this study may be employed for the development of new instruments. That is, selecting items investigated in this study for the scale, then typically explored using Exploratory Factor Anslysis (EFA) (Eckhaus, 2019), followed by Confirmatory Factor analysis (CFA).

\subsection{Supervision}

Supervising research students requires a lot of investment (Davidovitch \& Eckhaus, 2020b; Eckhaus \& Davidovitch, 2020b), and is considered a more prestigious stage in the hierarchy of academic achievements than frontal teaching, despite the critical importance of teaching (Davidovitch \& Eckhaus, 2019a, 2019b; Eckhaus \& Davidovitch, 2019a, 2019b), but it is also inferior to publications, which are dominant in the prestige front of the 
researcher (Davidovitch \& Eckhaus, 2018). The curriculum vitae of candidates up for promotion is supposed to include scientific supervision, but it is quite common for scientists who led Master's and PhD students to their destination but have insufficient publications to be passed over for promotion, while scientists who did not supervise many students but have a large number of publications will be promoted. One of the results is that in many institutions students find it hard to find a supervisor for their thesis. Moreover, capable researchers receive bonuses and various facilitations due to their success, while excellent lecturers are left with mere crumbs (Brew, 2003). Several studies proposed a solution regarding the continued work of retired experienced researchers, in supervising and guiding research students (Davidovitch \& Eckhaus, 2020a; Eckhaus \& Davidovitch, 2020a).

In recent years this tool is being gradually worn down, since the many students make it hard to provide close supervision and the internet is an opening that calls for "cut and paste". A large portion of students compose seminar papers as a collage of quotations, in many cases even without noting the source. This is also how they were taught by their high school teachers (Almog \& Almog, 2002). Hence, supervision is very meaningful in academic teaching for advanced degrees.

\subsection{Between the Student and the Supervisor}

Beside theoretical courses, the research track in advanced studies requires students to plan and carry out original independent research that is innovative and that contributes to promoting knowledge in their field, and to write a summarizing scientific essay. Every research student receives a supervisor, however the supervision approval by the staff member depends on the member's willingness to engage or accept the supervision of the potential student.

This willingness requires a meeting of interests. This means a research topic that interests both the student and the staff member, as well as a personal connection. The idea is usually proposed by the student, but it is not rare to see an initiative put forth by the supervisor, mostly as part of a large research project (Figlio \& Schapiro, 2017).

Students normally begin their search for a supervisor after the first year of their Master's studies, while PhD studies are predicated to begin with on finding a supervisor. Many departments hold familiarization days with supervisors. Staff members introduce themselves and their research fields and students can turn to anyone who appears suitable for supervision considering their fields of interest, available budget, and interpersonal chemistry. Sometimes, particularly in the case of interdisciplinary research, supervision is carried out by two supervisors, and in rarer cases even three or more.

The supervisor has a crucial role not only because the student's admission to $\mathrm{PhD}$ studies depends to begin with on the supervisor's consent, but rather also because he guides the course of the research and accompanies the student throughout the research study. In this respect, there is a significant difference between the hard and soft sciences, as work in the laboratory is performed on a daily basis and research students in chemistry, biology, and physics become part of the researcher's lab staff. In the soft sciences, supervision is carried out at present primarily by correspondence, with occasional meetings for purposes of guidance.

In most cases the supervisor is also one of the final evaluators of the research study, together with other judges, and can influence their choice. In addition, since advanced studies cover several years and have their ups and downs, one of the supervisor's roles is support and encouragement. Success or failure, which includes quitting, depend on many cases on the relationship that emerges between the supervisor and the student. The supervisor has an important role also after the degree is awarded: through letters of recommendation, professional contacts, and publication of joint articles (Cohen \& Davidovitch, 2016).

In the past, when students for advanced degrees were apprentices of the supervisor, the supervisor's identity was a status symbol, because the young student was considered the teacher's heir and successor. Today many staff members have a multitude of trainees and the personal relationship is usually weak.

\subsection{Is it Worth the Effort?}

In the past only a small proportion of Bachelor's degree graduates continued to study for an advanced degree, and specifically for a PhD. In recent years the numbers have risen significantly. For instance, from 1995 to 2014 the number of $\mathrm{PhD}$ graduates in OECD countries doubled, far more than the population increase. Master's and $\mathrm{PhD}$ studies were considered in the past so prestigious that no one dared doubt their value. Anyone who chose to study for an advanced degree and was admitted - was highly lauded. Today as well there seem to be good reasons to study for an advanced degree, the most important being that deep studies challenge thinking, widen one's horizons, uplift the soul, and raise one's self-esteem. This is an opportunity to devote most of one's time to research, to enter a rare academic and intellectual atmosphere, become familiar with fascinating worlds, get to 
know interesting people, innovate, and create. For many, independent work on an intellectual project that is also expected to discover new information - is a unique and exciting opportunity. Not to mention receiving close supervision that is often also challenging, which requires one to correct, hone, and improve, and particularly to meet the expectations of someone perceived as a learned person (Sinuany-Stern \& Davidovich, 2007).

Nonetheless, it is essential to recognize the changing times. At present, the signs are growing that the value of academic studies and of the academic degree is diminishing relative to the efforts required, and that the alternatives are worth more (Almog \& Almog, 2002).

\subsubsection{A Lengthy and Tiring Process}

The average time from beginning studies for a Master's degree until receiving a $\mathrm{PhD}$ is six (particularly in the "hard" subjects) to ten years (particularly in the "soft" subjects). Taking into account undergraduate studies as well, this is a lengthy period of time. Hence, it is no coincidence that about one third of all PhD students drop out of their studies before reaching their target (in the life sciences the proportion is even higher).

The length of the process has become a considerable disadvantage in recent years, for several reasons:

- In an era of instant gratification people are much less tolerant of lengthy tiring courses of study.

- In the past, lengthy studies suited those who designated themselves for a scientific career and were in no hurry. Many PhD students came from wealthy families who supported them during their studies. At present, most $\mathrm{PhD}$ students are not wealthy and are compelled to give up part of their ability to work and support themselves for many years.

- Academic studies leave the students outside the real world while their peers are advancing their careers and establishing themselves financially and family-wise.

- In an era of fast information, the slow pace of the PhD degree (particularly in the social sciences and humanities) endangers innovation and the sense of pioneering. By the time you manage to research, write, and have your work judged - the topic is no longer interesting, and in many cases no longer relevant.

- Uncertainty. Today students prefer to know in advance what they are getting into and what exactly will be demanded of them. In advanced studies there is very little certainty. When the $\mathrm{PhD}$ is sent to external judges - whose considerations are not transparent - the chances of rejection or delay are hard to foresee. Moreover, in a $\mathrm{PhD}$ by publication, which is based on publications in peer-reviewed journals, another uncertainty factor is involved: the editor of the journal and the external reviewers, over whom the supervisor and the school have no influence. The result is that research students enter a course of studies where the schools cannot show clear terms of success, and students might eventually be in for a real blow.

- Subsistence hardships. Master's studies, and particularly PhD studies, not only take a long time but also cost a lot. Studies are indeed partially or fully subsidized by many governments, but the total costs of the degree include not only tuition. In the past, a PhD facilitated a reasonable level of subsistence, through generous scholarships and jobs in research and as teaching assistants. At present, due to the financial difficulties of the schools, most research students are employed under contractors, in return for hourly wages, and receive student pay.

- Exploited workers. In recent years criticism of how supervisors exploit their students and research assistants has been growing. Exploitation includes a range of problematic behaviors: grey-area or criminal theft of data, copyrights, and rights to ideas; granting disproportionate weight (if mentioned at all) to the student in the list of study authors; unfair wages; taking undue advantage of one's authority (for instance, tasks that are unrelated to the research); etc. In most schools there are clear rules of ethics in this area, but many researchers know how to cut corners and take advantage of loopholes. In addition, studies and articles reveal that sexual harassment is not a rare occurrence in academia (towards both students and peers). In most schools there are indeed organs intended to deal with the phenomenon, but there is wide consensus among the experts that most of the abuse is not reported or silenced.

Notably, academia provides fertile grounds for negative elements in this area for two reasons: First of all, because the personal relationship formed between the supervisor and the students increases the potential of exploitation by staff members who are high on their own authority and ego. Secondly, because the student's absolute dependence on the supervisor makes it hard for students to respond with the necessary resolve and to complain. Such a complaint might involve not only unpleasantness but also termination of their studies, in which much effort and money have been invested.

- Unguaranteed intellectual challenge. In the past, academia was the main supplier of intellectual innovations and employed the best brains. Therefore, the experience of a higher education was enriching and unique and had no competition. But are present, a large part of staff members are far from being great 
scholars or innovators. Many serve instead as "science officials", whose papers are their labor. Even the most skilled find it hard to invest in their students, because as stated they are not rewarded for doing so.

Moreover, when the degree depends on publishing in journals, it is only natural that supervisors and students tend to choose subjects whose publication seems guaranteed. Hence, in the most critical stage in the scientist's life, when brains are still fresh, motivation high, and creativity ablaze, skilled people are compelled to produce conformist and anticipated articles.

$\mathrm{PhD}$ studies are less challenging today also due to the declining reading culture. In the past, it was customary to publish prominent theses in book form. Today it is harder to publish books in general, and all the more so in academic publications. Even when these are published - the number of readers is very small (Almog \& Almog, 2020).

In the past, $\mathrm{PhD}$ studies were attractive also because they allowed excelling students to study with other excelling students. But at present $\mathrm{PhD}$ studies are a breeding ground for different kinds of scientific novices. The lenient screening and the diminishing demands (even the demand for foreign languages is dropping or disappearing in some humanities departments), aside from at several selective prestigious schools, is producing large heterogeneous graduate classes that include, beside skilled young people, also complete morons Many $\mathrm{PhD}$ theses are submitted sloppily, in lame language, and with embarrassing methodological errors, not to mention a lack of creative interpretation. (It is not accidental that more and more private companies are emerging, offering to help with formulating theses, including gathering material, processing it, and even writing the final work, meaning: everything.) When this is the norm, judges are compelled to pass unsuitable work as well. The result is that many of those who boast a $\mathrm{PhD}$ are far from meeting the level expected of a scientist (Cohen, 2018).

Indeed, studies have found that many $\mathrm{PhD}$ students discover to their surprise and chagrin that they are not part of a lively intellectual scientific community. Considering this, it is hard to be surprised by a study conducted in the US, which found that no less than $40 \%$ of research students in the life and engineering sciences are indifferent towards or unsatisfied with their $\mathrm{PhD}$ study experience.

- It's not over even when its over. A PhD is a necessary but insufficient condition for an academic career. In the past, young people who earned a $\mathrm{PhD}$ would serve as interns for one to three years at as high standard a school as possible before submitting their candidacy for an academic position. This was customary and necessary due to the need to acquire experience in independent research and to accumulate research grants, publications, and recommendations. In the US and in other countries this stage is called "certification", "post-doc", and in Europe and Asia it is called "habilitation". The essential differences are that the post-doc usually precedes the formal entrance into the academic position, while "habilitation" is already part of the position and constitutes a period of candidacy before receiving tenure. Another difference is that the output of a post-doc is scientific publications, while the output of habilitation is often a $\mathrm{PhD}$-scope research thesis.

But what was once merely recommended has in recent years become the standard in most schools around the world. This means that the period of training and tests before submitting candidacy for a tenured position is now lengthy, while uncertainty has become chronic and includes financial hardship. Regretfully, studies show that not only is the chance of receiving an academic position after the post-doc very low (only a few percentages), rather the additional period does not train academics for work outside academia.

Recently, an initiative has suggested that $\mathrm{PhD}$ studies be split into two separate tracks: academic and professional. In several countries - such as the UK, US, France, and Germany - this split already exists in the fields of engineering, at least partially - side by side with the academic track that is adapted to industry, there is also an engineering track managed by an academic and a professional from the industry.

- High psychological cost. Nature psychological fatigue, anxiety, depression, and even suicidal thoughts. A survey among over 6,000 $\mathrm{PhD}$ students around the world in order to feel the pulse of science's future generation. The findings portray a worrying and depressing state of affairs (Almog \& Almog, 2020). Over one third of the PhD students noted their psychological state as a source of concern, and half were compelled to request psychological help in order to survive (mainly due to the pressure to publish).

Another study conducted in Belgium with thousands of $\mathrm{PhD}$ students in the exact sciences and the humanities, found that no less than half those surveyed had experienced mental distress. One in three were at risk of developing psychiatric disorders - twice that customary among the "very educated". Even in Ivy League universities the mental state of research students is not good. A study that sampled $\mathrm{PhD}$ students of economics in eight such schools in the US found that $18 \%$ of them had experienced different levels of anxiety and depression. Even graver, one of ten in the sample reported suicidal thoughts. 
In general, many $\mathrm{PhD}$ students find themselves in an academic cul-de-sac. On one hand, they lose the motivation to complete their studies, and on the other it is hard for them to let go of what has already been achieved with much money, work, and tears.

- Slight chance of finding a job. If only it would somehow be possible to suffer a temporary depression that leads to redemption, or at least to one's dream job; but even this proves an illusion. Surveys from around the world portray an identical picture: the discrepancy between the supply of jobs in academia and the demand is constantly growing, and the infinitesimal chance of securing a job turns advanced studies into a hazardous gamble. For instance:

- Only $12 \%$ of those who earn a PhD in the US and Canada will find a tenured academic position. In the UK and Australia the situation is even tougher, and less than 5\% of graduates will find a job.

- Every professor of engineering in the US supervises 7.8 $\mathrm{PhD}$ students on average throughout his or her career, but upon retirement vacates only one position.

- From 1982 to 2011, 800 thousand US students earned a PhD in the exact sciences and engineering, while in the same period only 100 thousand positions were added in schools of higher education.

- In the popular field of biomedicine, only one of every six $\mathrm{PhD}$ graduates receives the chance of applying for an academic position.

- In the humanities, the chance of receiving a position is almost nil due to the significant cuts.

In US English departments, for instance, the number of tenured positions has been reduced by over $40 \%$ in six years (2008-2014). The number of PhD students increased in that period by $26.10 \%$.

$\mathrm{PhD}$ studies, which are a requirement for an academic career, are a type of deception for another reason as well: Most of the people who choose this track are not aware of the fact that in contrast to the external image spread by schools of higher education the admission process of new faculty members in many schools is far from objective, fair, and professional, as customary in the independent labor market, and it is contaminated by protectionism, nepotism, and political and other biases (not one of our interviewees failed to note this). One of the reasons is the fact that many schools grant departments too much autonomy to select new faculty members. It is indeed customary to advertise tenders for new positions or those vacated, but in practice it is not rare for senior faculty members to use their contacts to bring in their own people or to prevent the acceptance of others (Milgram \& Davidovitch, 2010).

At present, the chance of $\mathrm{PhD}$ graduates finding a job in schools of higher education is slight, and it appears that elsewhere as well academic degrees are not such an advantage. One study indeed found that the chance of finding a job in the general labor market rises with the level of one's degree, but the difference between the chance of receiving the requested position with a Master's degree and with a $\mathrm{PhD}$ - is fairly negligible. As we noted in the chapter on education, many young $\mathrm{PhD}$ graduates find it difficult to land a job that will both support them and suit their expectations, among other things because they are perceived by the employers as "over-qualified". Many also have professional specialties that have no value outside the academic setting, and are drawn into a faltering career of research assistants and temporary teachers (Sperling, 2018).

Due to the significance of supervision, in this pioneer study we examined the association between the outputs of supervision and its nature (through e-mails, face-to-face, the student's independence). In addition, the association between the supervising lecturer's personal background (gender, age), professional background (faculty, tenure, excellence in teaching), and the supervision outputs (articles written, presentations at conferences) and nature of the supervision was explored. The purpose of the study was to explore items in depth so that they can be used in the development of a questionnaire exploring the association between supervision outputs and the nature of the supervision. 
Table 1. Questions for the supervisors

\begin{tabular}{ll}
\hline Item & \multicolumn{1}{c}{ Question } \\
\hline Q2.1 & Hours of supervision or meetings with the student at your initiative \\
Q2.3 & You feel that the efforts you put into the student's research are beyond expectations \\
Q2.4 & When writing papers with students on their research topics, the students are dominant \\
Q2.5 & Most of the papers I published in the last three years were with students on their research topic \\
Q2.6 & When appearing in conferences with students on their research topic, the students give the presentation \\
Q2.7 & Most of my contact with the students is by e-mail \\
Q2.8 & I don't often intervene in the students' manner of writing \\
Q2.9 & The students customarily use the assistance of an external factor for the purpose of data analysis \\
Q2.10 & I customarily form contact between all my supervised students through (a colloquium, regular \\
Q2.11 & I provide my students with assistance through my research grant \\
\hline
\end{tabular}

\section{Method}

\subsection{Initial Sample}

The questionnaire was distributed by means of Google Docs to senior faculty members at Ariel University who have experience with supervising students. Sixty completed questionnaires were collected. The descriptive statistics of the respondents are presented in Table 2 (in the column headed \% Resp.).

The survey included 11 closed-end items on a Likert scale of 1 (don't agree) to 5 (agree), for the following items presented at Table 1. One item was deleted because it was not well understood by respondents, resulting in 10 closed-end questions. Q1 was an optional details request; therefore, the items begin with Q2.

\subsection{Analysis}

We explored each of the questions in relation to the variables listed in Table 2.

In order to investigate relationships between the items we explore interaction effects between the all items. Statistical significant results are presented.

Statistical analyses employed were: T-Test, one-way ANOVA, two-way ANOVA, Scheffe post-hoc analysis.

\section{Results}

Table 2 presents the means and $\%$ of respondents for the variables investigated.

Below are the results for the significant statistical effect found between the variables.

Table 2. Variable means and $\%$ for respondents.

\begin{tabular}{|c|c|c|c|c|c|c|c|c|c|c|c|c|}
\hline Variable & Values & Q2.1 & $\mathrm{Q} 2.3$ & Q2.4 & Q2.5 & Q2.6 & Q2.7 & Q2.8 & Q2.9 & Q2.10 & Q2.11 & $\begin{array}{l}\% \\
\text { Resp }\end{array}$ \\
\hline \multirow{2}{*}{ Gender } & Female & 3.82 & 3.46 & 2.68 & 2.31 & 2.3 & 2.61 & 1.54 & 2.54 & 2.82 & 2.52 & 50.9 \\
\hline & Male & 3.68 & 3.36 & 2.67 & 2.46 & 2.59 & 2.39 & 1.82 & 2.37 & 3.33 & 2.96 & 49.1 \\
\hline \multirow[t]{3}{*}{ Age } & $41-49$ & 3.38 & 3.38 & 2.46 & 2.77 & 3.54 & 2.77 & 1.54 & 1.85 & 3.92 & 3.15 & 28.3 \\
\hline & $50-60$ & 3.76 & 3.82 & 2.94 & 2.53 & 3.25 & 2.53 & 1.71 & 3.06 & 3.12 & 2.65 & 37 \\
\hline & $61-85$ & 4.06 & 3 & 2.4 & 2.33 & 3.53 & 2.19 & 1.75 & 2.38 & 3.25 & 2.6 & 34.8 \\
\hline \multirow[t]{5}{*}{ Faculty } & Social & 3.4 & 3.2 & 2.86 & 2 & 3.36 & 2.4 & 1.8 & 2.79 & 3.14 & 2.69 & 37.5 \\
\hline & Health & 3.8 & 3.3 & 2.4 & 2.33 & 3.44 & 3.1 & $1.2^{*}$ & 3.2 & 3.5 & 2.6 & 25 \\
\hline & Nature & 4 & 3.5 & 2.67 & 3.17 & 3.67 & 1.67 & 1.83 & 1.17 & 3 & 3.33 & 15 \\
\hline & Architect & 4.5 & 4 & 2.5 & 1 & 1 & 3 & 3.5 & 3.5 & 4.5 & 2 & 5 \\
\hline & Engineer & 3.29 & 3.29 & 2.57 & 2.71 & 4.14 & 2.43 & 1.43 & 1.86 & 3.43 & 4 & 17.5 \\
\hline \multirow[t]{4}{*}{ Rank } & Lecturer & 4 & 3.44 & 2.89 & 1.63 & 3.29 & 2.67 & 1.67 & 2.75 & 3.13 & 2.13 & 15.3 \\
\hline & Senior Lecturer & 3.17 & 3.65 & 2.7 & 2.39 & 3.64 & 2.48 & 1.65 & 2.52 & 2.74 & 2.83 & 40.7 \\
\hline & Associate Professor & 4.08 & 6.42 & 2.55 & 2.75 & 3.42 & 2.33 & 1.33 & 2.67 & 3.08 & 3.18 & 20.3 \\
\hline & Full Professor & 4.2 & 2.8 & 2.7 & 2.6 & 3.5 & 2.4 & 1.8 & 1.9 & 3.3 & 2.7 & 16.9 \\
\hline \multirow[t]{2}{*}{ Tenure } & No & 3.71 & 3.47 & 3 & 2.24 & 3.35 & 2.41 & 2.12 & 2.53 & 3.12 & 2.44 & 30.9 \\
\hline & Yes & 3.68 & 3.38 & 2.54 & 2.54 & 3.35 & 2.54 & 1.57 & 2.41 & 2.95 & 2.81 & 69.1 \\
\hline Achieved & No & 3.57 & 3.21 & 2.64 & 2.15 & 3.68 & 2.54 & 1.64 & 2.41 & 2.78 & 2.59 & 48.3 \\
\hline Excellence & Yes & 3.86 & 3.69 & 2.75 & 2.59 & 3.21 & 2.41 & 1.72 & 2.52 & 3.31 & 2.82 & 51.7 \\
\hline
\end{tabular}




\subsection{Q2.3: Two-way Analysis of Variance}

The hypothesis that gender and age affect the reply to question Q2.3 was examined. The findings are presented in the Table 2.

Table 2. Two-way ANOVA effects of gender and age on Q2.3

\begin{tabular}{lllll}
\hline Gender & Age & Mean & Std. Deviation & $\mathrm{N}$ \\
\hline Female & $41-49$ & 3.13 & 0.991 & 8 \\
& $50-60$ & 4.33 & 0.707 & 9 \\
& $61-85$ & 2.4 & 0.894 & 5 \\
Male & Total & 3.45 & 1.143 & 22 \\
& $41-49$ & 3.8 & 1.095 & 5 \\
& $50-60$ & 3.25 & 1.282 & 8 \\
& $61-85$ & 3.27 & 1.009 & 11 \\
Total & Total & 3.38 & 1.096 & 24 \\
& $41-49$ & 3.38 & 1.044 & 13 \\
& $50-60$ & 3.82 & 1.131 & 17 \\
& $61-85$ & 3 & 1.033 & 16 \\
& Total & 3.41 & 1.107 & 46 \\
\hline
\end{tabular}

A two-way analysis of variance found a significant main effect for respondents' age $(F(2,40)=3.458, p<0.05)$. A significant effect was also found for the interaction between the variables of age and gender $(F(2,40)=4.423$, $\mathrm{p}<0.05$ ) (Figure 1).

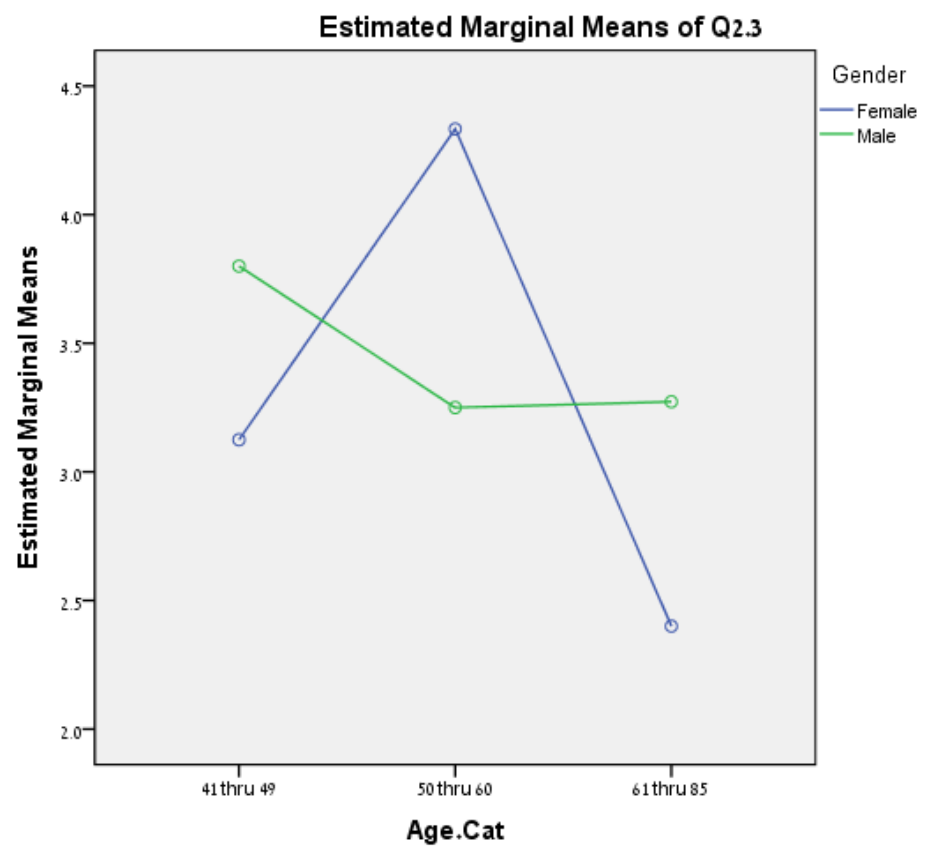

Figure 1. Interaction effect of age and gender on Q2.3

Figure 1 shows the interaction between age and gender with regard to replies to Q2.3. It can be seen that in the age category of 41-49 the difference between men and women's reply to the question is the smallest, in the age category 50-60 the difference is the largest, and in the age category 61-85 the difference is large. This means that the gender variable affects the reply to the question differently for each of the age categories, i.e., there is an interaction between the variables.

Since the interaction is significant, in order to explore which categories differ significantly a t-test was performed on the gender variable for each of the three age categories based on the reply to Q2.3. In the age category 50-60 a statistically significant difference was found between men and women $(\mathrm{t}=2.858, \mathrm{p}<0.05)$. Women's mean on this question $(\mathrm{M}=4.33, \mathrm{SD}=0.707)$ was higher than men's $(\mathrm{M}=3, \mathrm{SD}=1.155)$. The two other categories were not significant. 
The hypothesis that age and tenure affect the reply to Q2.3 was examined. The findings are presented in Table 3.

Table 3. Two-way ANOVA effects of age and tenure on Q2.3

\begin{tabular}{lllll}
\hline Age & Tenure & Mean & Std. Deviation & $\mathrm{N}$ \\
\hline $41-49$ & No & 2.33 & 1.528 & 3 \\
& Yes & 3.78 & 0.667 & 9 \\
& Total & 3.42 & 1.084 & 12 \\
$50-60$ & No & 4.5 & 1 & 4 \\
& Yes & 3.5 & 1.087 & 12 \\
& Total & 3.75 & 1.125 & 16 \\
$61-85$ & No & 3.2 & 0.837 & 5 \\
& Yes & 2.78 & 1.202 & 9 \\
& Total & 2.93 & 1.072 & 14 \\
Total & No & 3.42 & 1.311 & 12 \\
& Yes & 3.37 & 1.066 & 30 \\
& Total & 3.38 & 1.125 & 42 \\
\hline
\end{tabular}

In a two-way analysis of variance a significant main effect was found for the age variable $(\mathrm{F}(2,36)=3.76, \mathrm{p}<0.05)$. Moreover, a significant effect was found for the interaction between the variables of age and tenure $(\mathrm{F}(2,36)=3.79, \mathrm{p}<0.05)$ (Figure 2$)$.

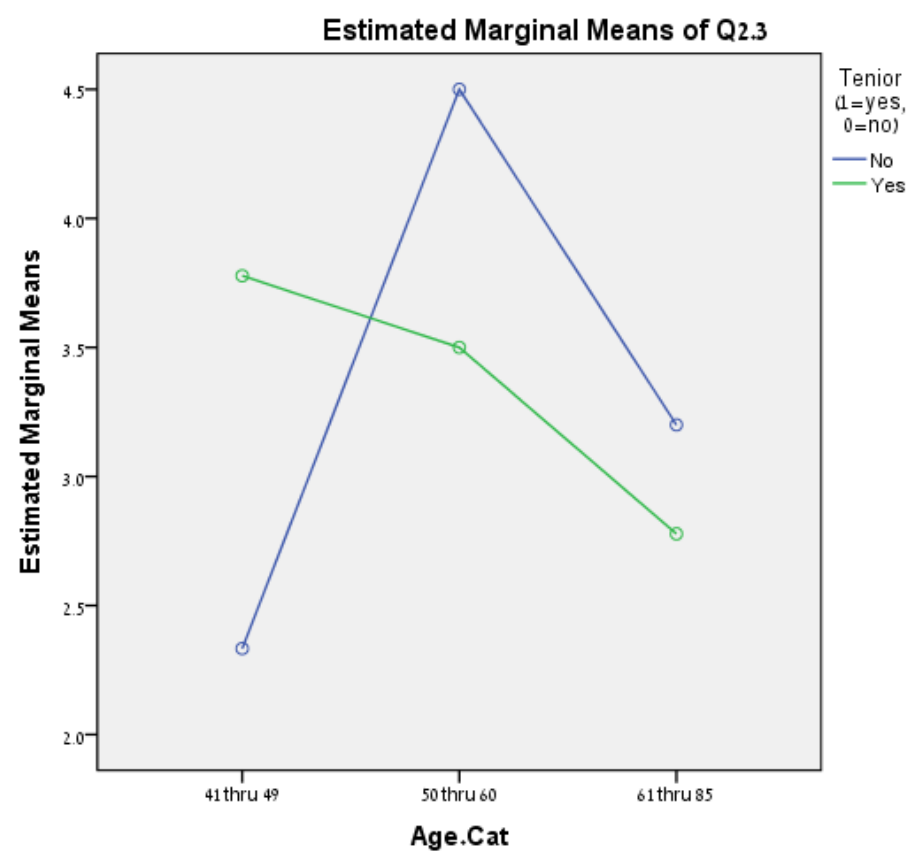

Figure 2. Interaction effect of age and tenure on Q2.3

Figure 2 shows the interaction between tenure and age with regard to the reply to Q2.3. It can be seen in ages 41-49 the largest difference was found in the group of tenured respondents compared to the untenured in response to the question. A smaller difference was found between the group of untenured respondents compared to the tenured in response to the question in ages 50-60, and the smallest difference was found in the group of untenured respondents compared to the tenured in response to the question in ages 61-85. This means that the age variable affects replies to the question differently for each of the tenure variable categories, i.e., there is an interaction between the variables.

Since the interaction is significant, in order to explore which categories show a statistically significant difference a t-test was performed on the variable of tenure for each of the age categories. Based on the reply to Q2.3 the age category 41-49 showed a statistically significant difference between tenured workers and untenured workers $(\mathrm{t}=-2.389, \mathrm{p}<0.05)$. The mean of the tenured to this question $(\mathrm{M}=3.78, \mathrm{SD}=0.667)$ was higher than the mean of the untenured $(\mathrm{M}=2.33, \mathrm{SD}=1.528)$. The two other categories were not significant. 
The hypothesis that age and teaching excellence affect the reply to Q2.3 was examined. The findings are presented in Table 4.

Table 4. Two-way ANOVA effects of age and excellence on Q2.3

\begin{tabular}{lllll}
\hline Age & Excellence & Mean & Std. Deviation & $\mathrm{N}$ \\
\hline $41-49$ & No & 2.75 & 1.258 & 4 \\
& Yes & 3.75 & 0.886 & 8 \\
& Total & 3.42 & 1.084 & 12 \\
$50-60$ & No & 4.17 & 0.753 & 6 \\
& Yes & 3.5 & 1.269 & 10 \\
& Total & 3.75 & 1.125 & 16 \\
$61-85$ & No & 2.6 & 0.843 & 10 \\
& Yes & 3.67 & 1.033 & 6 \\
& Total & 3 & 1.033 & 16 \\
Total & No & 3.1 & 1.119 & 20 \\
& Yes & 3.63 & 1.056 & 24 \\
& Total & 3.39 & 1.104 & 44 \\
\hline
\end{tabular}

A two-way analysis of variance found a significant effect for the interaction between the variables of age and excellence on the job $(\mathrm{F}(2,38)=3.331, \mathrm{p}<0.05)$ (Figure 3$)$.

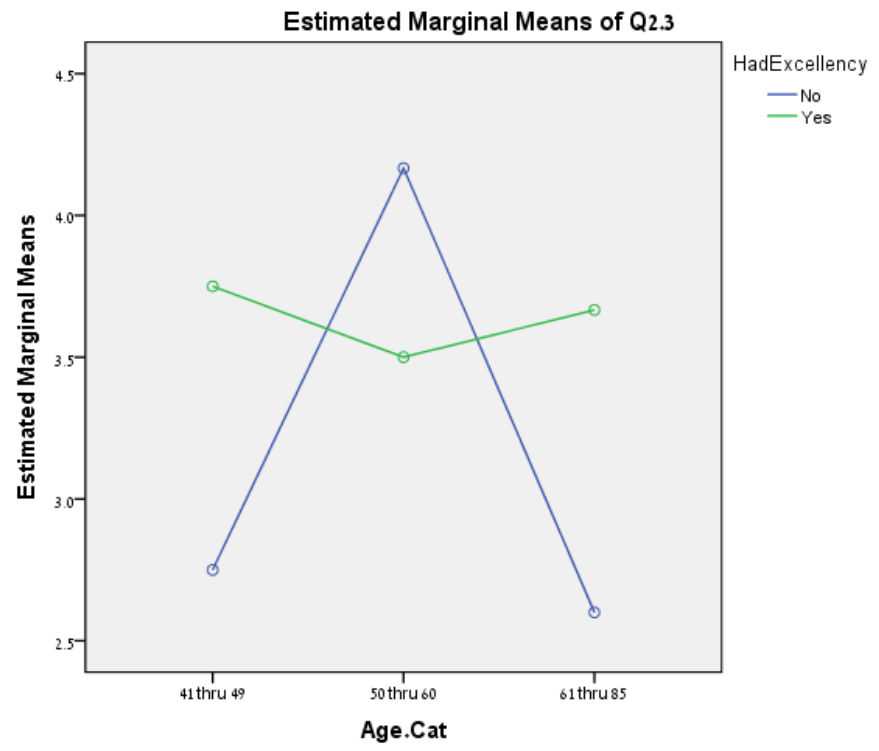

Figure 3. Interaction effect of age and excellence on Q2.3

Figure 3 shows the interaction between excellence in teaching and age regarding the reply to Q2.3. It is evident that the largest difference in reply to the question among the respondents with regard to excellence in teaching was found in the group of respondents aged 41-49, the smallest difference in response to the question among the respondents with regard to excellence in teaching was found among the group of respondents aged 50-60, and a large difference in response to the question was found among the respondents with regard to excellence in teaching in the group of respondents aged 61-85. This means that the age variable affects replies to the question differently for each category of the variable of teaching excellence. Namely, there is an interaction between the variables.

Since the interaction proved significant, in order to explore which categories show a statistically significant difference a t-test was performed for the variable of excellence in teaching for each of the age categories based on the reply to Q2.3. In the age category of 61-85 a statistical difference was found between those who excelled in teaching and those who did not $(\mathrm{t}=-2.256, \mathrm{p}<0.05)$. The mean of those who excelled in teaching for this question $(\mathrm{M}=3.67, \mathrm{SD}=1.033)$ was higher than the mean of those who did not excel $(\mathrm{M}=2.6, \mathrm{SD}=0.843)$. The two other categories were not significant. 


\subsubsection{One-way Analysis of Variance}

In order to explore whether there are differences in replies to Q2.6 between the different faculties, a one-way analysis of variance was conducted, finding a significant difference between the five faculties $(F(4,33)=2.731$, $\mathrm{p}<0.05)$.

A post-hoc Scheffe analysis showed that the reply to the question by staff members from the Faculty of Engineering $(\mathrm{M}=4.14, \mathrm{SD}=0.9)$ was significantly higher than the reply by staff members from the Faculty of Architecture $(\mathrm{M}=1, \mathrm{SD}=0.00)$.

3.2.2 Two-way Analysis of Variance

The hypothesis that gender and faculty affect the reply to Q2.6 was examined. The findings are presented in Table 5 .

Table 5. Two-way ANOVA effects of gender and faculty on Q2.6

\begin{tabular}{lllll}
\hline Gender & Faculty & Mean & Std. Deviation & $\mathrm{N}$ \\
\hline Female & Social & 2.57 & 1.134 & 7 \\
& Health & 4 & 0.816 & 7 \\
& Nature & 4 &. & 1 \\
& Engineer & 4 & 1.414 & 2 \\
& Total & 3.41 & 1.176 & 17 \\
Male & Social & 4.14 & 0.69 & 7 \\
& Health & 1.5 & 0.707 & 2 \\
& Nature & 3.6 & 1.517 & 5 \\
& Architect & 1 & 0.000 & 2 \\
& Engineer & 4.5 & 0.577 & 4 \\
& Total & 3.5 & 1.469 & 20 \\
& Social & 3.36 & 1.216 & 14 \\
& Health & 3.44 & 1.333 & 9 \\
& Nature & 3.67 & 1.366 & 6 \\
& Architect & 1 & 0.000 & 2 \\
& Engineer & 4.33 & 0.816 & 6 \\
& Total & 3.46 & 1.325 & 37 \\
\hline \multirow{6}{*}{ Total }
\end{tabular}

In a two-way analysis of variance, a significant main effect was found for respondents' faculty $(\mathrm{F}(4,28)=4.804$, $\mathrm{p}<0.01)$. Moreover, a significant effect was found for the interaction between the variables of gender and faculty $(\mathrm{F}(3,28)=6.266, \mathrm{p}<0.01)($ Figure 4$)$. 


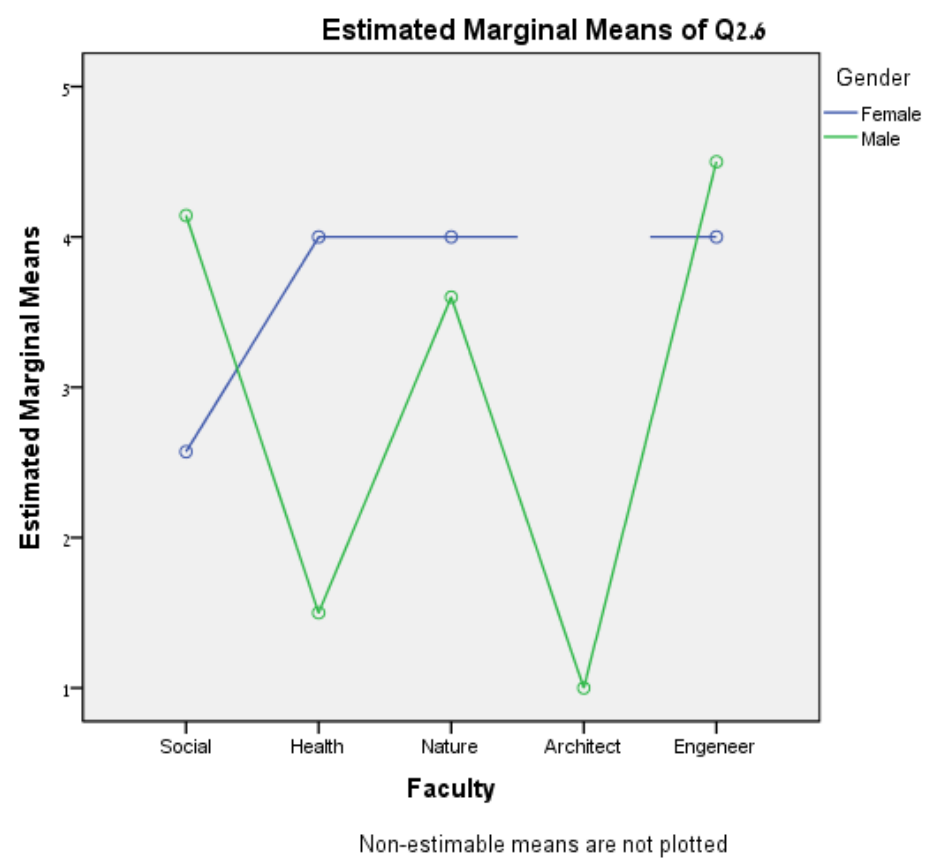

Figure 4. Interaction effect of faculty and gender on Q2.6

Figure 4 shows the interaction between faculty and gender regarding the reply to Q2.6. It is evident that in the Faculty of Health Sciences the difference in replies to the question between men and women was the largest, in the Faculty of Society Sciences there was a large difference, in the Faculty of Natural Sciences and Engineering the difference was very small, and in the Faculty of Architecture no difference was found because no women participated in the study. This means that the gender variable affects replies to the question differently for each category of the faculty variable, i.e., there is an interaction between the variables.

Since the interaction was significant, in order to explore in which categories there is a statistically significant difference, a t-test was conducted for the variable of gender for each of the five faculty categories based on the reply to Q2.6.

In the Faculty of Social Sciences a statistically significant difference was found between men and women $(\mathrm{t}=-2.757, \mathrm{p}<0.05)$. Men's mean on this question $(\mathrm{M}=4.14, \mathrm{SD}=0.69)$ was higher than women's $(\mathrm{M}=2.67$, $\mathrm{SD}=1.211)$. In addition, in the Faculty of Health Sciences a statistically significant difference was found between men and women $(t=3.889, \mathrm{p}<0.01)$. Women's mean on this question $(\mathrm{M}=4, \mathrm{SD}=0.816)$ was higher than men's $(\mathrm{M}=1.5, \mathrm{SD}=0.707)$. The three other categories were not significant.

\subsection{Q2.7: One-way Analysis of Variance}

The hypothesis that gender and age affect the reply to Q2.7 was examined. The findings are presented in Table 6.

Table 6. Two-way ANOVA effects of gender and age on Q2.7

\begin{tabular}{lllll}
\hline Gender & Age & Mean & Std. Deviation & $\mathrm{N}$ \\
\hline Female & $41-49$ & 3.5 & 1.069 & 8 \\
& $50-60$ & 2.22 & 1.394 & 9 \\
& $61-85$ & 2.4 & 1.14 & 5 \\
Male & Total & 2.73 & 1.316 & 22 \\
& $41-49$ & 1.6 & 0.548 & 5 \\
& $50-60$ & 2.88 & 0.991 & 8 \\
& $61-85$ & 2.09 & 0.831 & 11 \\
Total & Total & 2.25 & 0.944 & 24 \\
& $41-49$ & 2.77 & 1.301 & 13 \\
& $50-60$ & 2.53 & 1.231 & 17 \\
& $61-85$ & 2.19 & 0.911 & 16 \\
& Total & 2.48 & 1.150 & 46 \\
\hline
\end{tabular}

In a two-way analysis of variance, a significant effect was found for the interaction between the variables of gender and age $(F(2,40)=5.822, \mathrm{p}<0.01)$ (Figure 5). 


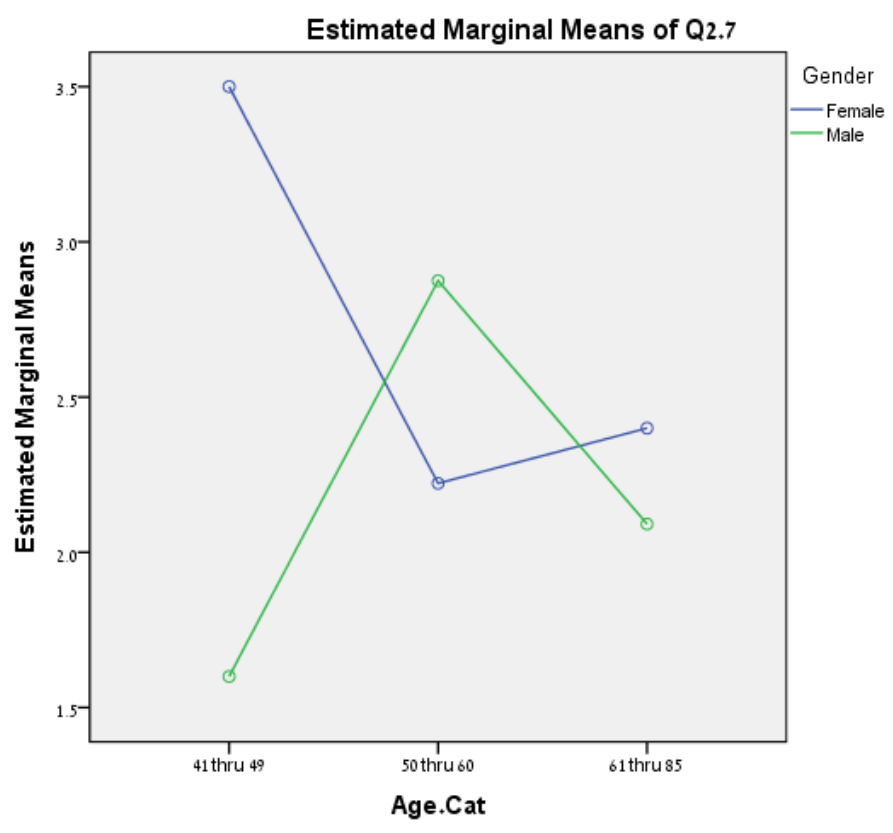

Figure 5. Interaction effect of age and gender on Q2.7

Figure 5 shows the interaction between age and gender with regard to the reply to Q2.7. It is evident that in the age category of 41-49 the difference between men and women in their reply to the question is the largest, in the age category of 50-60 the difference is large, and in the age category of 61-85 the difference is smallest. This means that the variable of gender affects the response to the question differently for each category of the age variable, i.e., there is an interaction between the variables.

Since the interaction is significant, in order to explore which categories are significantly different a t-test was held for the variable of gender for each of the three age categories based on the reply to Q2.7. In age category 41-49 a statistically significant difference was found between men and women $(t=3.566, p<0.01)$, where the women's mean on this question $(\mathrm{M}=3.57, \mathrm{SD}=1.134)$ was higher than the men's $(\mathrm{M}=1.6, \mathrm{SD}=0.548)$. The two other categories were not significant.

\subsection{Q2.8: One-way Analysis of Variance}

In order to explore whether there are differences in the reply to Q2.8 between the different faculties, a one-way analysis of variance was held and a significant difference was found between the five faculties $(F(4,35)=3.147$, $\mathrm{p}<0.05)$. A post-hoc Scheffe analysis showed that the reply to the question by staff members from the Faculty of Architecture $(M=3.5, S D=2.12)$ was significantly higher than the response by staff members from the Faculty of Natural Sciences $(\mathrm{M}=1.2, \mathrm{SD}=0.42)$.

\section{$3.5 Q 2.9$}

\subsubsection{One-way Analysis of Variance}

In order to explore whether there are differences in the reply to Q2.9 between the different faculties, a one-way analysis of variance was held. However the results showed that the homogeneity of variances test was significant $(p<.05)$, such that the assumption of variance equality was not maintained. Therefore, a nonparametric Kruskal-Wallis test was conducted to equalize the populations. A difference was found in the reply to Q2.9 between the five different faculties of the respondents. The findings indicate a significant difference between the groups $\left(X^{2}(4)=10.741, p<0.05\right)$, where the highest mean of replies to the question was by staff members of the Faculty of Architecture $(\mathrm{M}=3.5, \mathrm{SD}=0.707)$, followed by the mean of replies to the question by staff members of the Faculty of Health Sciences $(\mathrm{M}=3.2, \mathrm{SD}=1.398)$, the mean of replies to the question by staff members of the Faculty of Social Sciences $(M=2.79, S D=1.424)$, the mean of replies to the question by staff members from the Faculty of Engineering $(\mathrm{M}=1.86, \mathrm{SD}=1.215)$, and the lowest mean of replies to the question was among staff members of the Faculty of Natural Sciences $(\mathrm{M}=1.17, \mathrm{SD}=0.408)$.

\subsubsection{Two-way Analysis of Variance}

The hypothesis that gender and excellence in teaching affect the reply to Q2.9 was examined. The findings are 
presented in Table 7.

Table 7. Two-way ANOVA effects of gender and excellence on Q2.9

\begin{tabular}{lllll}
\hline Gender & Excellence & Mean & Std. Deviation & $\mathrm{N}$ \\
\hline Female & No & 2.93 & 1.58 & 15 \\
& Yes & 2.09 & 1.3 & 11 \\
& Total & 2.58 & 1.501 & 26 \\
Male & No & 1.64 & 1.027 & 11 \\
& Yes & 2.87 & 1.356 & 15 \\
& Total & 2.35 & 1.355 & 26 \\
Total & No & 2.38 & 1.499 & 26 \\
& Yes & 2.54 & 1.363 & 26 \\
& Total & 2.46 & 1.421 & 52 \\
\hline
\end{tabular}

A two-way analysis of variance found a significant effect of the interaction between the variables of gender and excellence on the job $(F(1,48)=7.425, \mathrm{p}<0.01)$ (Figure 6).

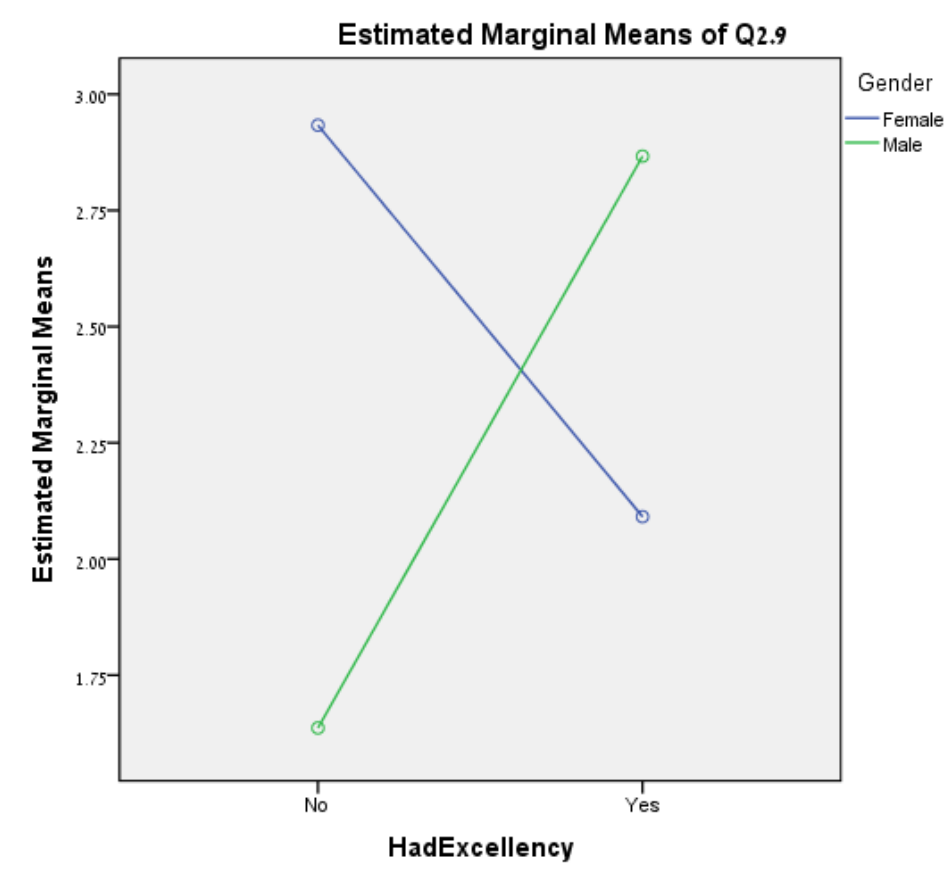

Figure 6. Effect of interaction between excellence and gender on Q2.9

Figure 6 shows the interaction between excellence in teaching and gender as affecting the reply to Q2.9. It is evident that in the group of respondents who did not excel in teaching a large difference was found between men and women's replies to the question, while in the group of respondents who excelled in teaching a smaller difference was found. This means that the variable of gender affects replies to the question differently for each category of the variable of teaching excellence, i.e., there is an interaction between the variables.

Since the interaction was significant, in order to explore between which categories was there a statistically significant difference a t-test was performed with the variable of gender, for each of the two categories concerning teaching excellence, based on the reply to Q2.9. In the category of not excelling in teaching a statistically significant difference was found between men and women $(\mathrm{t}=2.533, \mathrm{p}<0.05)$, where women's mean on this question $(\mathrm{M}=2.93, \mathrm{SD}=)$ was higher than men's $(\mathrm{M}=1.64, \mathrm{SD}=1.027)$. The other category was not significant.

\section{Discussion}

As stated, this is a pioneer study exploring the association between supervision outputs and the nature of the supervision. In addition, the association between the personal and professional background of the supervising lecturer and supervision outputs and nature of the supervision. The purpose of the study was to thoroughly 
explore items to be used in developing a questionnaire exploring the association between supervision outputs and the nature of the supervision.

The research findings indicate regarding the supervising lecturer's efforts in supervising the research student as surpassing expectations: women aged 50-60 felt that the efforts invested in the student's research surpass expectations, more than did men in this age group. Tenured staff aged 41-49 felt that the efforts invested in the student's research surpass expectations, more than did untenured staff in this age group. In addition, those who excel in teaching from among the 61-85 age group felt that the efforts invested in the student's research surpass expectations, more than did those who do not excel from among this age group. With regard to supervision outputs, a difference was found between faculties for presenting at conferences with students on their research topic: Staff members from the Faculty of Engineering let students present their research topics at conferences much more than staff members from the Faculty of Architecture and from the Faculty of Social Sciences. Male staff members let students present their research topic at conferences much more than do female staff members, but in the Faculty of Health Sciences women let students present their research topic at conferences more than do men. With regard to students' manner of communication, women aged 41-49 communicate with students by e-mail the most, more than men in this age group. Regarding manner of supervision, staff members from the Faculty of Natural Sciences were found to intervene more in how students' articles are written than their colleagues from other faculties. Moreover, students were found to employ the help of an external factor for purposes of data analysis - Staff members from the School of Architecture claim that the students are accustomed to utilizing the help of an external factor for purposes of data analysis much more than staff members from Health Sciences, the Faculty of Social Sciences, the Faculty of Engineering, and finally from the Faculty of Natural Sciences, who close the list. In addition, women who excel in teaching thought that students are accustomed to utilizing external factors for the purpose of data analysis much more than did men.

The findings of this study might have practical effects for establishing the output-guided relationship in research supervision and for establishing the practical association between the nature of the supervision, the lecturer's personal background, professional background, and supervision outputs and the nature of the supervision. These findings constitute a foundation for methodological thinking in the supervisory work of staff members, a topic that has considerable meaning for the initial steps taken by young student researchers, as well as for systematic establishment of the pattern of academic supervision, which although not frontal teaching may be even more demanding.

\section{Acknowledgments}

Many thanks to research assistant Shir Alima for her contribution to this study.

\section{References}

Almog, T., \& Almog, A. (2020). All the lies of academia. Tel aviv: Yedhiot Sfarim. [Hebrew].

Brew, A. (2003). Teaching and research: New relationships and their implications for inquiry-based teaching and learning in higher education. Higher Education Research \& Development, 22(1), 3-18. https://doi.org/10.1080/0729436032000056571

Cohen, E. (2018). Public policy for regulating the interaction between labor market supply and higher education demand - Israel as a case study. International Journal of Higher Education, 7(6), 150-160. https://doi.org/10.5430/ijhe.v7n6p150

Cohen, E., \& Davidovitch, N. (2016). Regulation of academia in Israel: Legislation, policy, and market forces. Journal of Education and Learning, 5(4), 165-180. https://doi.org/10.5539/jel.v5n4p165

Davidovitch, N., \& Eckhaus, E. (2018). Effect of faculty on research cooperation and publication: Employing natural language processing. Economics and Sociology, 11(4), 173-180. http://dx.doi.org/10.14254/2071-789X.2018/11-4/11

Davidovitch, N., \& Eckhaus, E. (2019a). Student evaluation of lecturers - what do faculty members think about the damage caused by teaching surveys? Higher Education Studies, 9(3), 12-21. https://doi.org/10.5539/hes.v9n3p12

Davidovitch, N., \& Eckhaus, E. (2019b). Teaching students to think - faculty recommendations for teaching evaluations employing automated content analysis. International Journal of Higher Education, 8(3), 83-93. https://doi.org/10.5430/ijhe.v8n3p83

Davidovitch, N., \& Eckhaus, E. (2020a). The attitude of academic faculty to continued work by faculty members after reaching retirement age. Economics \& Sociology, 13(2), 123-135. 
https://doi.org/10.14254/2071-789X.2020/13-2/9

Davidovitch, N., \& Eckhaus, E. (2020b). The relationship between students' research motivation, capacity for independent work, and research outputs: defining the good advisee using natural language processing. Journal of Education and Learning, 9(5), 38-44. https://doi.org/10.5539/jel.v9n5p38

Dupuis, M. J., Crossler, R. E., \& Endicott-Popovsky, B. (2016). Measuring the human factor in information security and privacy. Paper presented at the 2016 49th Hawaii International Conference on System Sciences (HICSS). https://doi.org/10.1109/HICSS.2016.459

Eckhaus, E. (2019). How to be Happy. Retrieved from http://www.artistila.com/how-to-by-happy

Eckhaus, E., \& Davidovitch, N. (2019a). How do academic faculty members perceive the effect of teaching surveys completed by students on appointment and promotion processes at academic institutions? A case study. International Journal of Higher Education, 8(1), 171-180. https://doi.org/10.5430/ijhe.v8n1p171

Eckhaus, E., \& Davidovitch, N. (2019b). Potential for blocking advancement: teaching surveys for student evaluation of lecturers. International Journal of Educational Methodology, 5(3), 401-406. https://doi.org/10.12973/ijem.5.3.401

Eckhaus, E., \& Davidovitch, N. (2020a). The changing of the guard in academia and academic research leadership--employing natural language processing. International Education Studies, 13(8), 95-102. https://doi.org/10.5539/ies.v13n8p95

Eckhaus, E., \& Davidovitch, N. (2020b). Peer assessments of research advisors and effects on investments in teaching. Laplage Em Revista, 6(Especial), 49-56. https://doi.org/10.24115/S2446-622020206Especial938p.49-56

Farooq, R. (2018). How to design and frame a questionnaire Innovations in Measuring and Evaluating Scientific Information. IGI Global. pp. 50-60. https://doi.org/10.4018/978-1-5225-3457-0.ch004

Figlio, D. N., \& Schapiro, M. (2017). Are great teachers poor scholars. Evidence Speaks Reports, 2(6), 1-7.

Milgram, R. M., \& Davidovitch, N. (2010). Creative thinking and lecturer effectiveness in higher education. The International Journal of Creativity \& Problem Solving, 20(1), 7-14.

Sachs, S. K. (2004). Evaluation of teacher attributes as predictors of success in urban schools. Journal of Teacher Education, 55(2), 177-187. https://doi.org/10.1177/0022487103261569

Sinuany-Stern, Z. \& Davidovich N. (2007). The relationship between teaching and research activities of faculty: Case study of College of Judea and Samaria. Moscow State University Journal of Education, Pedagogical series, 2. [Russian]

Sperling, D. (2018). Changes in review trends of academic writing of books in the $21^{\text {st }}$ century. Mofet Institute Information Center. [Hebrew]

Väätäjä, H., Koponen, T., \& Roto, V. (2009). Developing practical tools for user experience evaluation: A case from mobile news journalism. Paper presented at the European Conference on Cognitive Ergonomics: Designing beyond the Output---Understanding Activity and User Experience in Ubiquitous Environments. https://doi.org/10.1145/1952222.1952252

\section{Copyrights}

Copyright for this article is retained by the author(s), with first publication rights granted to the journal.

This is an open-access article distributed under the terms and conditions of the Creative Commons Attribution license (http://creativecommons.org/licenses/by/4.0/). 